\title{
Arbor
}

\section{La evolución de la seguridad en los museos}

\author{
Francisco de la Fuente
}

Arbor CLXIX, 667-668 (Julio-Agosto 2001), 711-723 pp.

Cuando me incorporé a la Fundación Thyssen-Bornemisza en Enero de 1992, diez meses antes de la apertura al público, entre las muchas tareas a realizar estaba la organización de los transportes de la colección, la confección de los planes de autoprotección, procedimientos diarios, manual de servicio para los vigilantes de la empresa de seguridad, etc.

A cada uno de estos manuales se le dio el sentido que todos sabemos que ha de tener, y se diseñó el dispositivo de seguridad humano para que por un lado pudieran responder las consultas que les hiciera el público, y por otro, y como tarea principal lógicamente, la vigilancia de las salas y la custodia de las obras de arte.

En cuanto a este último aspecto, nos centramos fundamentalmente en la prevención de las posibles agresiones o robos hacia las obras expuestas y se establecieron los dispositivos precisos para procurar que en la medida de lo posible esto no se produjera.

Hasta aquí todo parecía lógico sobre todo por la idea que tanto mis supervisores como yo mismo teníamos de que el público en los museos debía tener un comportamiento bueno, que no se hablaría en voz alta, no se tocarían las obras etc.; quizás extrapolando al resto de las personas nuestra idea de cual debía ser nuestro comportamiento a la hora de visitar un museo.

No obstante, una vez abierto al público y a través tanto de las conversaciones que manteníamos con los vigilantes como de las observaciones de los supervisores de seguridad y de las mías, nos fuimos dando cuenta de cual era verdaderamente el comportamiento del público en las salas y nos percatamos de que a los problemas menores de que se pudiera fumar en los servicios, que se tiraran papeles al suelo 
y otras cosas que se corrigen con facilidad, se sumaban otros mas preocupantes como era que los visitantes se aproximaban excesivamente a las obras expuestas y que incluso las tocaban.

Por ello, y una vez normalizado el día a día en el museo, tomamos la determinación de verificar en qué medida nos debían preocupar estos dos últimos problemas y para ello era necesario hacernos cargo de la incidencia real tanto de uno como de otro y saber si esto podría llegar a representar un peligro para la conservación de las obras. Como Restauración nos dijo que evidentemente esto no era conveniente en modo alguno para las obras, decidimos iniciar el Estudio de Comportamiento del Público (ECP).

Dicho estudio se inició confeccionando un parte de trabajo que debían rellenar todos los vigilantes de sala, en el que además de los datos de identificación de estos, se refleja el número de walkie asignado así como su estado para controlar el uso que se hace de estos. Consta a su vez de dos grupos de datos como son por un lado las informaciones que los vigilantes dan al público sobre algunos de los aspectos del museo que nos interesa controlar para corregir las posibles carencias de información así como lo que al visitante mas le interesa sobre nuestro museo; y por otro, y como datos mas interesantes para nosotros, las intervenciones que estos realizan con los visitantes. En la cara posterior del parte, se refleja el número de catálogo de la obra afectada, para incluir este dato en una base de datos de la colección como se verá mas adelante.

Los Supervisores de seguridad recogen diariamente los partes, los agrupan por semanas y posteriormente se introducen en un ordenador en el cual creamos una aplicación específica para el control de todo esto, y nos totaliza todo por meses, años, conceptos etc. Así mismo, como sabemos qué obra es la que ha sufrido la incidencia, esto se refleja en la base de datos, y así conocemos en todo momento por meses, el número de aproximaciones excesivas o toques de cada una de las obras de la colección.

Desde el primer momento nos dimos cuenta que las cifras que nos salían sobre todo en estos dos conceptos de aproximaciones excesivas y toques eran muy elevadas, lo que nos hizo, y a través de conversaciones con el Restaurador, el personal de Conservación y el resto de personas implicadas, quienes en todo momento se han volcado con nosotros, reflexionar sobre si no sería necesario plantearnos nuestra idea inicial de lo que debería ser la vigilancia en salas.

Tenemos que tener en cuenta que los museos debemos poner todos los medios a nuestro alcance para que las obras no sean objeto ni 
de robos ni de agresiones, ya que al estar al alcance del público, están expuestas a cualquier tipo de acciones como las anteriores; pero teniendo en cuenta la incidencia que este tipo de acciones tienen por ejemplo durante un año en los museos que cuentan con un sistema de seguridad fiable en todo el mundo. En realidad este tipo de acciones tienen una incidencia baja, centrándose los robos sobre todo en lugares que o bien tienen un grado de protección lejos de lo recomendable tales como iglesias, casas particulares e incluso muchas galerías de arte. Lo que ocurre es que cuando sucede en museos importantes, suele ser una acción muy relevante, ya sea por la publicidad que se le da al hecho, o porque la obra robada o agredida sea muy importante.

En realidad, si calculáramos porcentualmente el número de robos o agresiones en los museos por ejemplo de Europa, con respecto al número de visitantes anuales, el nivel de incidencias de este tipo podríamos considerarlo prácticamente cero, lo que no impide que tomemos todas las medidas necesarias para evitarlo, que en la mayoría de los casos son soluciones no muy costosas pero que requieren unas mínimas medidas organizativas.

Por ello, y a la vista de los resultados obtenidos en nuestro estudio, creo que hemos de centrar nuestra atención además de en las agresiones antes mencionadas, sobre todo en paliar los efectos que sobre las obras expuestas tienen las acciones del público, ya que se producen de manera continua, en nuestro caso 9 horas al día 309 días al año.

Hay que tener en cuenta que dichas acciones no se realizan con ánimo de efectuar un daño, si no que están motivadas por la falta de conciencia de los visitantes hacia el daño que se puede producir a una obra de arte por el mero hecho de tocarla y la falta de costumbre a la hora de visitar museos, que redunda en un mal uso de los mismos.

Hay que considerar que la piel, y sobre todo las manos, contienen todo tipo de substancias tales como grasas, suciedad, polvo etc., que al tocar una obra quedan depositadas en la capa protectora formada por los barnices con los que se recubre la capa pictórica para proteger esta lo mejor posible de este tipo de substancias. Así mismo, el toque continuo produce una abrasión que puede originar que las capas protectoras de las obras quede o muy dañada o eliminada totalmente, con lo que la capa que debería estar protegida, pasa a estar expuesta al daño directamente. Como ejemplo de esto, recordemos la exposición de esculturas de Botero llevada a cabo en el Paseo del Prado de Madrid, que al cabo de pocas semanas mostraban sus partes mas sobresalientes 
absolutamente bruñidas debido a que el toque continuo por parte de los visitantes eliminó la pátina protectora del bronce en esos lugares.

El depósito constante de las substancias antes mencionadas en la capa de barnices, así como los productos procedentes de la respiración tales como monóxido de carbono, vapor de agua, etc., que se depositan por una aproximación excesiva, como mal menor pueden producir un oscurecimiento de la capa de barniz, que puede llegar a imposibilitar la correcta observación del cuadro y a que se dejen de observar detalles importantes del mismo; lo que obliga a retirarlo durante muchos días de las salas para proceder a su limpieza y en algunos casos a la sustitución de la capa de barniz protector. Por supuesto, las obras que no disponen de dicha capa de barniz, como son los Maestros Modernos, son mucho mas delicadas desde este punto de vista.

Los conceptos generales que manejamos dentro de este estudio son:

Informaciones. - Los vigilantes reflejan el número de preguntas que los visitantes les hacen sobre horarios, obras, servicios, ubicación de cafetería, baños etc. Estos conceptos al principio eran mas, pero a medida que el estudio iba avanzando, al detectar qué preguntas eran las mas abundantes, pudimos ir corrigiendo todo aquello que suponía un problema para los visitantes, y a medida que los resultados del estudio iban dejando alguno de estos conceptos a cero, se iban eliminando de los partes pues ya no era necesario tenerlos en consideración al haber desaparecido el origen del problema con la corrección efectuada. Si Seguridad es capaz de obtener este tipo de datos y trasladarlos al área afectada, se puede corregir aquello que suponga un problema para los visitantes o para la organización interna de los servicios propios del museo.

Intervenciones.- Aquí se refleja todo aquello que representa una intervención dé los vigilantes ante una acción incorrecta de los visitantes, tales como tocar obras, aproximaciones excesivas, uso indebido de cámaras, explicaciones no autorizadas, llevar mochilas a la espalda o subirse a las tarimas de las ventanas.

He de hacer constar como pueden ver, que el estudio se ha realizado en nuestros museos de Madrid y Barcelona y en las exposiciones temporales llevadas a cabo en nuestro museo de Madrid. Así mismo, pueden ver que conceptos tales como Explicaciones están a cero, y esto está motivado porque a la vista de los resultados de este estudio se modificaron algunas cosas en las visitas de los grupos guiados, que dieron como resultado una mejor gestión de los mismos y por lo tanto un problema menos para los vigilantes en las salas. 
La evolución de la seguridad en los museos

Resumen mensual:

Total mes por tipo de actuación (julio)

\begin{tabular}{|c|c|c|c|}
\hline & \multicolumn{3}{|c|}{ PORCENTAJES } \\
\hline & Madrid & Barcelona & Temporal \\
\hline \multicolumn{4}{|c|}{ Informaciones } \\
\hline Obras & 3,31 & 6,83 & 0,68 \\
\hline Salas & 4,39 & 13,01 & 0,70 \\
\hline Itinerario & 5,69 & 12,42 & 0,87 \\
\hline Cafetería & 2,93 & 0,00 & 0,43 \\
\hline Horarios & 1,43 & 7,47 & 0,06 \\
\hline Totales & 17,75 & 39,72 & 2,75 \\
\hline \multicolumn{4}{|c|}{ Intervenciones } \\
\hline Tocar obras & 1,29 & 0,12 & 0,46 \\
\hline Proximidad & 9,23 & 18,28 & 1,79 \\
\hline Cámaras & 0,33 & 2,55 & 0,08 \\
\hline Explicaciones & 0,00 & 0,00 & 0,00 \\
\hline Mochilas & 2,66 & 0,28 & 0,41 \\
\hline Tarimas & 3,05 & 0,00 & 0,08 \\
\hline Totales & 16,56 & 21,24 & 2,78 \\
\hline
\end{tabular}

Se reflejan los porcentajes de actuaciones, ya que son las cifras significativas, porque dado que el estudio se ha realizado en varios museos que han colaborado con nosotros y han dado resultados similares, lo único que queda es extrapolarlo a cada uno teniendo en cuenta el número de visitantes anuales que se tengan, ya que estos son muy diferentes, encontrándonos museos que tienen 50.000 visitantes anuales, hasta los que tienen 1.500 .000 o mas.

Como se puede ver en el resumen mensual, se producen situaciones muy dispares según el lugar donde se realiza la toma de datos y esto es así por varios motivos:

- Ubicación geográfica.- Es evidente que el nivel cultural de los habitantes de una zona, su mayor costumbre en visitar museos, y una educación encaminada hacia el respeto a las obras de arte, provoca un menor número de toques hacia las obras. Se puede observar esto en los toques hacia las obras en Barcelona, que representa un $0,12 \%$ frente al $1,29 \%$ en Madrid. Esto no quiere decir que el nivel cultural en Madrid 
sea muy inferior, pues en Barcelona los visitantes son mayoritariamente del lugar y en Madrid se distribuyen al 50\% entre visitantes de toda España y extranjeros, y estos últimos dan tantos problemas o mas que los españoles, que suelen reaccionar mejor ante las indicaciones de los vigilantes y entienden cuales son nuestras motivaciones al intervenir.

- Características del lugar.- El comportamiento de los visitantes en un museo luminoso, con techos relativamente altos, pintado con colores claros etc., es mas relajado que en otros en los que el ambiente sea mas pesado, mas academicista, y por lo tanto se originan mayores problemas de comportamiento en los primeros. Esto se hace evidente en el museo de Madrid, pues los visitantes de la exposición permanente son prácticamente los mismos que en las temporales, y sin embargo el comportamiento varía notablemente como se puede ver en la tabla de total mes. Esto es debido a que las salas temporales, en contraposición a las permanentes, no tienen ventanas pues se sitúan en el sótano primero, los techos son mucho mas bajos, las paredes suelen estar pintadas de colores mas oscuros y la iluminación es menos intensa.

Se da además la circunstancia de que el museo de Barcelona está ubicado en un monasterio de clausura, en un ambiente que invita al recogimiento, y los visitantes suelen realizar la visita con mayor sosiego y tranquilidad, y en la mayoría de los casos hablando en voz baja, y no solo en nuestras salas, si no en el resto del monasterio donde pueden acceder.

En cuanto al apartado Proximidad, he de aclarar que como se ha establecido una separación mínima a las obras de $60 \mathrm{~cm}$, que es mas o menos la distancia a la que se colocan los cordones de separación, pero los visitantes traspasan esa distancia para leer las cartelas explicativas de cada obra, los vigilantes no intervienen hasta que consideran que la distancia es lo suficientemente corta como para representar un peligro para la obra, con lo que esto pasa a ser un tanto subjetivo quedando a la experiencia de los vigilantes el momento de intervenir. Por ello este concepto pasa a ser casi el doble en Barcelona, pues los cordones están colocados a mayor distancia y los visitantes han de acercarse desde mas distancia a las cartelas para leerlas, por lo que se podría decir que se traspasa el límite de peligro con mas facilidad al considerarse que este está a mayor distancia que en Madrid.

Con respecto a los sistemas separadores del público, estos pueden ser varios: cordones, cintas pegadas al suelo, etc. Cada uno tiene un 
poder disuasivo distinto al resto, por lo que si en la misma sala ponemos cordones y cintas, los visitantes respetaran con mas facilidad los cordones al ser elementos mas disuasivos, y respetaran menos las cintas. Por lo tanto, en una misma sala o se ponen unos $u$ otros, pero no los dos combinados, pues entonces el de menor poder disuasivo queda prácticamente anulado.

En muchos museos son poco dados a incorporar estos elementos en las salas aduciendo razones estéticas, sin darse cuenta de que es fundamental tanto para la labor de los vigilantes contar con ellos, como para la propia conservación de las obras. La incorporación de cristales a las obras como justificación para no poner separadores no es motivo suficiente a mi juicio ya que estos producen siempre gran cantidad de reflejos que imposibilitan la correcta observación del cuadro, a los que se suman las huellas de los dedos de los visitantes; además hacen más compleja la labor de los equipos de Montaje, ya que estos han de estar limpiando contantemente los cristales. Otra consideración es que en caso de rotura del cristal por algún motivo, este puede producir grandes daños a la obra.

La colocación de los elementos separadores, a la vista de los resultados obtenidos, me parece fundamental, ya que a los visitantes hay que establecerles la separación mínima que se ha de respetar a juicio de los Conservadores, y darle a los vigilantes un elemento de referencia a la hora de calibrar en qué momento pueden llamar la atención a un visitante por incumplir esta regla, ya que de lo contrario sería tan subjetivo tanto por parte de los vigilantes como de los visitantes decidir si se ha traspasado la distancia de por ejemplo $60 \mathrm{~cm}$. que podemos haber incluido en la información de los folletos que se entregan a la entrada, que además nunca se leen los visitantes, y que puede llegar a ser una fuente de problemas inagotable, y suponer una incomodidad para los visitantes, a los que hemos de procurar una estancia lo mas agradable posible. Por ello lo mejor es que esté todo perfectamente claro y no se susciten dudas por ninguna parte.

Otra razón que creo fundamental para la colocación de los elementos separadores, es que a través de la observación en salas, la grabación de imágenes etc., nos hemos podido dar cuenta de que los toques a las obras se producen prácticamente siempre en los mismos sitios, es decir, que debido a que puede haber un detalle muy bien realizado o muy realista, un detalle iconográfico que se reconoce con facilidad, un paisaje que se ha visitado con anterioridad 
y se ve representado en el cuadro y muchos otros motivos; esas zonas de los cuadros están sujetas a sufrir en mayor medida las aproximaciones excesivas y los toques, por lo que el peligro pasa a ser mayor, ya que si consideramos un número de toques determinado dentro de toda una colección, podría parecernos que no son muchos, pero si esos mismos toques los circunscribimos solo a las obras que se tocan en realidad ya que hay muchas que no se tocan, y dentro de aquellas solo a las zonas que antes hemos mencionado, el problema se incrementa pues dichas zonas sufrirán un deterioro mayor que el resto y al ser, por lo expuesto anteriormente, en la mayoría de los casos detalles fundamentales dentro de la composición de la obra, esta podría quedar muy desvirtuada.

Tanto para decidir si se incorporan o no, como para ver de qué clase serían, se ha de contar siempre con la opinión del departamento de seguridad ya que somos los únicos que conocemos con certeza la problemática de los visitantes en nuestro museo.

Ocurre además, que si en una sala se colocan separadores y en otra no, los visitantes tienen la impresión de que en aquellos sitios donde no los hay, se pueden aproximar a los cuadros sin ningún problema, por lo que lo mas recomendable sería colocarlos en todo el espacio de exhibición, que por otro lado es lo que solemos hacer en la sala de exposiciones temporales y por ello el porcentaje de aproximaciones excesivas es notablemente inferior.

Con respecto a esto, a través de los datos que hemos recabado en nuestro estudio, así como de las imágenes obtenidas en las salas, nos hemos podido dar cuenta que la forma de realizar la obra es un factor fundamental a la hora de tocarla y donde se toca, ya que si tenemos en cuenta que en la mayoría de las composiciones hay dos elementos como son las líneas de fuga y el centro de fuga que marcan la perspectiva del cuadro, las personas que saben de arte pero no de conservación, al explicar esto a terceras personas y al hacer hincapié en ello, suelen tocar las obras en esos lugares, que sufren un deterioro mayor al resto. Para que se comprenda mejor esto, lo representaré gráficamente.

En las imágenes que hemos tomado en las salas para su análisis, se observan claramente el comportamiento del público a la hora de visualizar las obras así como al dar las explicaciones oportunas, observando que los guías de los grupos tienen mucha costumbre de acercarse excesivamente, ya que al ser personas que poseen unos conocimientos mucho mas amplios de la habitual, y ser su labor mostrar los detalles que al profano se le escapan, ese aumento de 


\section{La evolución de la seguridad en los museos}

las explicaciones dan lugar a mostrar detalles en los cuadros que se señalan acercándose excesivamente a la zona de la obra donde se está dando la explicación o a tocarla, con lo que indirectamente están maleducando a los que les observan.

Composición piramidal

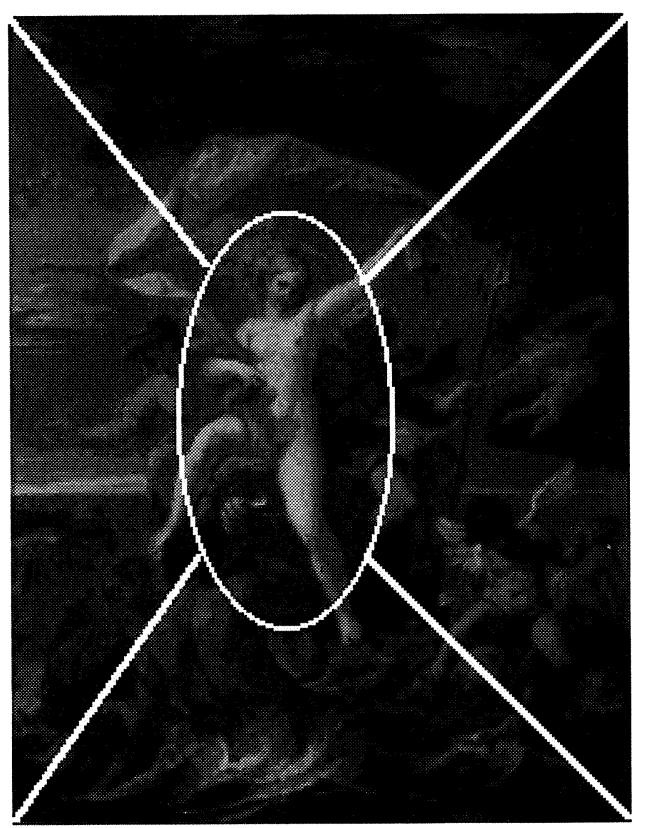

Composición en triángulo

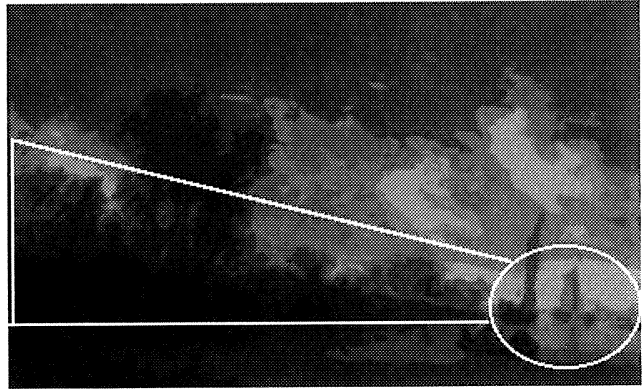

Hay muchos otros tipos de composición existentes. Como se puede ver, tanto desde el punto de vista de Seguridad como de Restauración, si además de lo habitual, se tiene en cuenta también esto, se podrá lograr una mejor conservación de las obras expuestas.

Tanto en los conceptos de aproximaciones excesivas como toques a las obras, se da la circunstancia de que aquellas en las que la capa pictórica es plana, es decir, que no tiene relieve como sucede en los maestros antiguos, los visitantes no las tocan tanto como aquellas realizadas al pastel u óleo, cuya capa pictórica, al tener mas relieve, el sentido del tacto puede aportar mas información y por lo tanto se tocan mas, por lo que hay que tener un cuidado muy grande con las esculturas, ya que en este caso esto se incrementa notablemente. El nivel de detalle de la propia obra, que sea muy conocida o que sea muy importante dentro de la obra de un autor, también son factores importantes tanto para los toques como las aproximaciones. 
Hay que tener mucho cuidado con los folletos, bastones y demás objetos alargados que se lleven en las manos, pues son utilizados habitualmente para señalar detalles en los cuadros, lo que hace aumentar el peligro de daños a las obras, como veremos en el vídeo realizado en una de nuestras salas.

Evidentemente, si dado el conocimiento que Seguridad tiene de todas estas incidencias, las trasladamos al departamento de Restauración, este puede tomar la determinación de efectuar un control mas exhaustivo sobre aquellas obras que sufren mas las acciones del público, o tomar la determinación de protegerlas especialmente.

Si además, se produce el préstamo de una obra que sabemos es mas proclive a este tipo de acciones, podemos pedir al museo que nos la solicita, que se tomen unas precauciones determinadas durante el período de tiempo en que permanece en sus manos.

Si los porcentajes que mostrábamos anteriormente los extrapolamos a un museo del que conozcamos el número de visitantes anuales, nos podremos hacer una idea de la importancia que este problema tiene en realidad, y tomar las medidas oportunas, realizando un estudio «in situ» de la realidad de cada museo, para tomar las medidas necesarias que nos permitan reducir estas cifras al mínimo, ya que hay que tener en cuenta que ni las aproximaciones excesivas ni los toques los vamos a poder eliminar totalmente, ya que no es un problema de los museos, si no de que los visitantes sean conscientes del peligro que este tipo de acciones representa y de lo delicadas que son las obras de arte.

En general, podemos considerar que para mantener este tipo de acciones en un nivel lo mas bajo posible, o reducir significativamente este tipo de acciones, se ha de trabajar en varias direcciones como ha sido en nuestro caso las siguientes:

Un aumento de la profesionalidad y efectividad de la vigilancia en salas originado por una cada vez mayor experiencia y profesionalidad de los vigilantes . Esto se consigue por varias vías, por un lado un plan de formación adecuado, y por otro, a la labor realizada por los Supervisores de seguridad realizando una selección del personal mas idóneo para llevar a cabo esto y un trabajo diario de contacto con los vigilantes para ir inculcándoselo y haciéndoles ver cuales son nuestras motivaciones al hacer según qué cosas.

En cuanto al plan de formación que mantenemos en nuestro museo, me gustaría hacer hincapié sobre este, ya que creo que es absolutamente fundamental a la hora de plantearse un Departamento de Seguridad con un grado de efectividad mayor al habitual, ya que, considerando la responsabilidad tan grande que supone la custodia de objetos que 
son de imposible restitución, y que forman parte del legado de la humanidad, no hay que escatimar esfuerzos en todo lo que esté en nuestras manos, y la formación es indispensable para conseguir esto. Hay que tener muy en cuenta, que el personal que presta su servicio en salas, cada vez en mayor número procede de empresas externas que suministran este personal, y que en muchos casos no tienen esa sensibilidad necesaria hacia la custodia de las obras de arte, por lo que es preciso que el titular del museo, se implique no solo en la confección del plan de formación y le dé la orientación que crea mas oportuna, si no que debe tomar parte activa en dicha formación, dando las explicaciones necesarias para que se entienda lo que se quiere lograr, ya que los formadores de las empresas, por mucho que quieran, no van a poder dar esa visión tan exacta de las necesidades, riesgos $\mathrm{y}$ complicaciones que se pueden encontrar.

Por ello en nuestro caso, tanto en la formación inicial como en la de reciclaje, participamos siempre explicando lo que queremos lograr, si no que tratamos de sensibilizar al personal, mostrándoles estadísticas, imágenes grabadas en salas, y en general transmitiéndoles nuestras experiencias para que no solo se sensibilicen hacia cual es su verdadero papel, sino también indicándoles qué es lo que se van a encontrar en salas cuando realicen su labor, y así lograr que desde el primer momento la realicen con el mayor grado de efectividad posible, evitando así las lagunas que se pueden producir al incorporar personal nuevo y con falta de experiencia en esta labor.

La colocación de los elementos separadores del público cada año en mayor número, que ha originado una menor problemática en las salas y la consecución de lo expuesto con anterioridad.

Una buena colaboración y comprensión mutua con Conservación, Registro y Restauración fundamentalmente, que somos quienes realizamos nuestra labor directamente con las obras expuestas.

En general las razones pueden ser varias, pero hay que tener en cuenta que hemos conseguido reducir este tipo de acciones del público hacia las obras en mas de dos tercios desde el inicio del estudio hasta la actualidad, y llevando a cabo además una reducción de la plantilla de vigilantes pasando desde los 55 puestos que había en 1992, hasta los 32 que existen en la actualidad, lo que nos ha permitido dimensionar la plantilla de vigilantes de acuerdo a las necesidades reales del servicio, lo que conlleva un planteamiento y desarrollo del departamento de seguridad equilibrando los gastos de explotación del mismo.

Como se puede ver, gracias a la labor de investigación realizada durante tantos años, en nuestro caso, nos planteamos el punto de 
vista de la seguridad, también desde el punto de vista de la conservación de las obras, lo que es enormemente inhabitual, y esto es gracias al entendimiento que a través de este estudio hemos tenido de los riesgos a los que se somete las obras de arte por el mero hecho de estar expuestas. Este entendimiento nos facilita que tanto la formación del personal de seguridad, como su mentalización a la hora de entender cual es su verdadera labor en un museo, sea mas avanzada y sensible hacia lo que es objeto de su custodia y la importancia de realizarla correctamente.

Ahora bien, hemos visto cual es el problema que se origina en los museos, por el mero hecho de estar abiertos al público, y una serie de medidas para con el personal de vigilancia en salas, que al menos en nuestro caso, ha dado unos resultados bastante buenos, y se ha conseguido paliar esto en gran medida, no obstante, hemos de tener en cuenta que la vigilancia humana es muy imperfecta, porque por lo general no se tiene el número de vigilantes apropiado, ya que hay museos sobre todo fuera de España, en los que podemos ver un vigilantes para Siete y mas salas, porque los vigilantes no pueden estar mirando a todas partes en todo momento, porque hay diferentes motivos por lo que pueden distraerse, etc., es por ello, por lo que cada vez toman mas importancia los sistemas de seguridad, no como substitutivos de la vigilancia humana, si no como un apoyo a esa vigilancia, y como forma de cubrir aquellas deficiencias que se producen, como se ha mencionado anteriormente.

Por parte de las empresas que suministran este personal, hay bastantes reticencias a la hora de hablar de sistemas, porque entienden que podrían llegar a sustituir a sus vigilantes, y se está cometiendo un gran error, ya que pasaran muchos años antes de que un sistema o máquina sea capaz de eso, y deberían tener en cuenta que los sistemas de apoyo de los que hablamos, supondrían un soporte fundamental para la labor de vigilancia, y una posibilidad menos de que se produzcan errores de vigilancia, que no solo redundarían en un perjuicio de imagen para las empresas, si no también una mayor seguridad para las obras expuestas, ya que hemos de tener siempre muy en cuenta la importancia de los bienes que estamos protegiendo, su importancia social y cultural, y la imposibilidad de restitución en caso de robo o daños graves.

Es por ello, que los museos, y sus responsables tales como Conservadores y Restauradores, deben ser mas abiertos a las innovaciones, ya que aunque no es nuestro caso, hay muchos museos que se oponen abiertamente ante algo tan sencillo como poner unos simples cordones 
de separación ante las obras, aduciendo poco estudiadas razones estéticas, en contraposición a los beneficios obtenidos.

Por otro lado, las empresas de desarrollo de sistemas, han de desarrollar estos, pensando siempre o asesorándose adecuadamente, sobre qué se puede incorporar a una obra de arte, ya que estas admiten pocos elementos adosados a cualquiera de sus superficies dado que podrían dañarlas con muchísima facilidad, y es por ello, que determinados desarrollos para museos nunca han tenido una implantación adecuada dada la imposibilidad de su colocación en las obras, por no haber tenido en cuenta lo antes mencionado.

Todo ello me hace pensar que la investigación y el desarrollo de sistemas conjuntamente entre los museos y las ingenierías de seguridad, darían unos frutos que beneficiarían enormemente tanto a los Museos como a las empresas prestatarias tanto de servicios de vigilancia como de instalaciones, pudiendo así conseguir un nivel de seguridad posiblemente sin igual en el mundo de la seguridad, ya que podríamos paliar los daños a las obras producidos por este tipo de acciones involuntarias de los visitantes, ya que el mandato fundamental de los museos es la conservación y exhibición de las obras de arte para que generaciones venideras puedan contemplar con la misma admiración con que nosotros lo hacemos ahora, la belleza surgida de la mano del hombre. 